THIURSDAY, JANUARY 29, 1874

\section{THE DUTY OF ELECTORS}

$\mathrm{I}$ his address to his Greenwich constituents $\mathrm{Mr}$. Gladstone has undoubtedly attacked a weak point of human nature, by his announcement of a large balance, the promise of the removal of the income-tax, and other reductions in taxation; but those who really have the welfare of their country at heart cannot help feeling that, by making one doubtful good all-prominent, he has placed too far in the background many of those points which are daily becoming of more and more importance to the national welfare. Our country depends for its high position among nations, not only on its resources in coal and iron, but also, and more securely, on the mental capacity of its people, whose peculiarity is that they have the power of always using the resources at their disposal to betteradvantage than any others. We in nearly all cases have taken the lead in invention. A discovery, for instance, is made by which the amount of coal required to produce a certain amount of useful work is diminished greatly; this is adopted by others of ourselves, and is gradually spread to other countries, not however before sufficient time has elapsed to place us on the way to another method, which will have as great advantages over the new one as that had over the one which preceded it. There are those amongst us who, with our national tendency to depreciate our own abilities and resources, carefully compile statistics show that our gradual decline and destruction are inevitable in a certain definite number of years. They, however, inevitably leave out of the question the potentiality, as it may be termed, of the British brain.

But how is it that we are able to maintain this high position of progressive discovery? This is a question which may be well asked. The answer is not difficult to find. It is on account of the thoroughness of the work done by some of the scientific members of the community, who but too often use their best efforts, involuntarily though it may be, to the working out of those inductions which lead to the discovery of new methods that prove so invaluable to their fellow-creatures, and so often unremunerative to themselves. There are many who must feel that it is not too early to make it a part of all Government legislation, that more stress be laid on and more direct pecuniary assistance be given to such unremunerative scientific work, and encouragement offered for the production of it in greater quantity, so as to secure more of its invaluable results.

It may be said, and it is said by some, that we have gone on very well as yet without any great encouragement in this direction; but this is the old argument over again ; we are now in a very different position to what we were formerly. When Science was in its infancy, it was not so essential to the production of good work that those who made the greatest strides should know much of the investigations of those who preceded them, nor of the principles of the sciences, by the employment of which alone they can expect to advance. But the last half century has been so prolific in scientific method and detail, that any one ignorant of all its branches, however great his ability, can have little or no chance of making fresh improvements or VOL. $1 \mathrm{x},-\mathrm{No}[222$ discoveries. What was not essential formerly is essential now ; and just as the standard of general education is much higher at the present time than it was some years ago, so must the scientiñ education be.

But there is only one method of improving scientific ecucation satisfactorily, and that is by making scientific work more possible and lucrative. A young man does not commence physics or chemistry or biology until he has really begun the battle of life; his mind is scarcely fit for it before ; he must therefore, when he takes them up, see clearly a livelihood ahead. Such a livelihood at present is little more than a phantom. The prospect of a post in any Government institution, such as the British Museum, for example, is, to say the most, to scarcely a pittance, and there are many of the best workers who would undergo many privations rather than have to devote the greater part of their lives to the drudgery of an educational appointment. Most scientific men do not expect to become rich on their avocation; the inherent pleasure of their subject compensates to a certain extent for the diminished income; but they must live, and living means more than obtaining an income which is insufficient to allow of their maintaining the social position to which they are born, or to which their education has brought them.

Such being the case, ought not the nation in a fresh Parliamentary election to lay some stress on the improvements that are indispensable for the healthy progress of scientific thought? Why does Mr. Gladstone's interest in the higher Education begin and end with Ireland-can it have any reference to party questions? Why is there all too slight a reference to the University question and no reference at all to the Report of the Royal Commission which has recently been issuedis it because Mr. Gladstone knows that there are many Conservatives much more liberal and large-minded than the Liberals themselves on this subject?

Is there no feeling throughout the country on the subject of Museums, or the ever-growing necessity for a Minister of Education? Mr. Gladstone may well be excused from referring to these topics in his "prolix" manifesto, but are all the Constituencies to neglect them? Is the Sectarian or the Licensed-Victualler to be the only man who shall require his candidate to render a reasonto state his views? Our point is, that every voter in the kingdom has now an opportunity of helping on the cause of Science and Education by insisting upon his representative having ideas-and right ideas-on these questions.

Why should there not, among the numerous influential scientific societies which are spread through the country, be formed organised committees whose duty shall be to use their influence in representing their requirements to the candidates for parliamentary election, and doing all in their power to get their wants respected and complied with? Again, why should not those bodies, like the University of London, with a large number of scientific voters, and a representative, do all in their power to return for their member one who has the interests of Science and the higher education at heart, and who will do all he can to put these interests in the best light? That such will not be done by the University of London at least, will be evident if Mr. Lowe is again returned as their member at the 
coming election; for his principles of action are understood; his views with regard to the Universities and the higher teaching generally are known ; and his unwillingness, even to consider the desirability of raising the salaries of the scientific officers of the British $\mathrm{Mu}$ seum to the level of those of ordinary Government officials is before the world. There is no doubt that he has forfeited all claim, to the support either of the Scientific or the Medical Graduates of the important Corporation which he represents.

$=$

\section{PHYSICAL GEOGRAPHY}

Physical Geography, in its Relation to the Prevailing Winds and Currents. By John Knox Laughton, M.A., F.R.A.S., Mathematical and Naval Insiructor at the Royal Naval College. Second Ed. (J. D. Potter, I873.) The Ocean: its Tides and Currents, and their Causes. By William Leighton Jordan. (Longmans, 1873.)

THE first part of Mr. Laughton's work consists of a comprehensive and valuable summary of the present state of our knowledge of the prevailing Winds in different parts of the globe ; on the basis of which he proceeds to examine into the commonly-received theory of Atmospheric Circulation, and pronounces that "it describes the phenomena which do not exist, and misrepresents, or does not account for, phenomena which do." The second part treats of the Currents of the Ocean; and these (following Major Rennell) he attributes for the most part to the winds prevailing in the localities in which they originate, their effects being variously modified by coast-lines, the meeting of other currents, \&c. We believe that he is quite justified in upholding this general doctrine, and in repudiating the notion of Captain Maury that differences of temperature, excess of evaporation, \&c., can sustain the Gulf Stream or any great oceanic current. But he rides his hobby a great deal too hard, when he affirms that under no circumstances can these agencies produce currents; going so far as to attribute the in-current of the Strait of Gibraltar to the vis-à-tergo of the Gulf Stream. As well might he attribute to it the constant current which sets over the bar of the Karaboghaz or Black Gulf on the eastern side of the Caspian, and carries (according to the computation of Von Bär) 350,000 tons of salt a day into this great natural salt-pan, the water (which the natives fancy must have some subterranean outlet) being all got rid of by evaporation. According to Sir John Herschel's computations, the excess of evaporation from the Mediterranean area, over the return of water by rain, would require twelve Niles to supply it ; and as there is only one Nile, and as Captain Wharton's recent researches in the Dardanelles show that the Black Sea sends very little of its riverwater into the Mediterranean (the supply poured in by the Danube, the Don, the Dnieper, and the Dniester, being very little more than sufficient to make up for the evaporation of the Black Sea itself), it is obvious that an enormous deficiency must exist, after every allowance has been made for the Rhone, the Ebro, and the Po, which are the only considerable rivers, beside the Nile, that pour their waters direct into the Mediterranean basin.

Mr. Laughton does not seem to have made himself as well acquainted as a Government naval instructor might have been expected to be, with recent contributions to Oceanic Hydrography. Thus he repeats the statement of his first edition,'that the Gulf Stream rushes through the Florida Channel at a rate varying from 80 to 120 miles a day; whereas the Admiralty Pilot Chart, based on the most trustworthy information, makes the annual average only 48 miles per day. He does not deign to notice the arguments adduced by Dr. Carpenter in his last report to the Royal Society, which have satisfied many eminent authorities that the amelioration of the climate of North Western Europe is due, not to the true Gulf Stream or Florida Current, but to a slow north-easterly movement of warm water sustained by thermal influences alone. He repeats (p. 200) the old fallacy that the cold of the oceanbottom is "due to the great depth, to the impermeability of water by the sun's rays;" as if this had not been disproved by the fact, that the bottom-temperature of the Mediterranean, at depths ranging to 2,000 fathoms, is from $54^{\circ}$ to $56^{\circ}$, whilst that of the Atlantic at similar depths and under the same parallel is twenty degrees lower. And in p. 250 he makes the astounding statement that "the gradual closing up of the channels [through which the Gulf Stream flows], by the ceaseless work of the polypes, has, by diminishing the outlet, increased the force of the stream;" which is tantamount to saying that the stream of water which issues from a fire-engine has a greater force than that which works its pumps! If we had only to narrow an outlet to create force, we need not be afraid of the exhaustion of our coal.

We recommend $\mathrm{Mr}$. Laughton, before he issues another edition of his book, to dismiss from his mind, if he can, all prejudice in favour of his particular theory, and to open his mind more fully to the evidence of a vertical Oceanic circulation, which he already partly admits, and which is not in the least inconsistent with his fundamental principle (in which we entirely accord) of the maintenance of the horizontal circulation of the great Ocean-basins by the movements of the atmosphere.

The title of Mr. Jordan's book is very misleading ; for, although professing to treat of the tides and currents of the Ocean, he devotes the greater part of his 344 octavo pages to an exposition of what may be called the Jordanian (in opposition to the Newtonian) system of Astronomy. This system is based on the doctrine of inertion, by which Mr. J. means the inherent tendency of all motion to come to an end. The only motor force he admits is that of gravitation; and he considers himself to have proved that the revolutions of the planets round the sun are due to the opposition between solar gravitation and astral gravitation, "so that, in their courses, they are borne smoothly along the lines of equilibrium lying between opposing forces of gravitation." He also maintains that "the rotation of a sphere tends to cause surrounding bodies to revolve around it ; "and that, in this manner, the rotation of the earth from west to east tends to carry the moon in the same direction, its "lagging behind" beng due to "astral gravitation."

The application of Mr. Jordan's theory of inertion to the movements of the ocean is very obvious. Reasoning upon the fact that when a vessel containing water is made to rotate, " $t$ he water tends to maintain its position, and therefore has a relative motion over the surface of the vessel in the opposite direction to that in which 